Internat. J. Math. \& Math. Sci.

Vol. 23, No. 7 (2000) 507-511

S0161171200002258

(C) Hindawi Publishing Corp.

\title{
A THEOREM OF MEIR-KEELER TYPE REVISITED
}

\author{
Y. J. CHO, P. P. MURTHY, and G. JUNGCK
}

(Received 1 October 1998)

\begin{abstract}
In 1993, the authors presented a fixed point theorem of Meir-Keeler type. The proposed proof of a lemma-on which the said theorem depends on-is invalid. In this note, we alter the statement of this lemma and give a valid proof thereof, so that the main result of the previous paper is still true.
\end{abstract}

Keywords and phrases. Compatible maps of type (A), a generalized $(\epsilon, \delta)-\{S, T\}$-contraction, common fixed point.

2000 Mathematics Subject Classification. Primary 54H25, 47H10.

In 1993, we introduced the concept of compatible maps of type $(A)$ and "proved" the following theorem.

THEOREM 1 [1, Theorem 3.2]. Let $A, B, S$ and $T$ be mappings of a complete metric space $(X, d)$. Suppose that the pair $\{A, B\}$ is a generalized $(\epsilon, \delta)-\{S, T\}$-contraction with $\delta$ lower semi-continuous. If the following conditions are satisfied:

(i) one of $A, B, S$ or $T$ is continuous, and

(ii) the pairs $A, S$ and $B, T$ are compatible of type (A) on $X$, then $A, B, S$ and $T$ have a unique common fixed point in $X$.

The purpose of this note is to ensure that the above is indeed true. This is necessary since the proof of Theorem 1 relies on Lemma 3.1 in [1]. However, the proof of part (1) of this lemma is faulty and the proof of part (2) is not "tight." In the following, we provide a thorough and complete proof of Lemma 4 below which is a "reshuffled and revamped" version of Lemma 3.1 in [1]. This accomplishes our mission, since the proof of Theorem 1 is valid if the lemma is true.

The proof of part (3) of Lemma 4 below is much like the proof of Lemma 3.1(c) in [2] with minor initial modifications. We include all the proof of part (3) for ease of reading and completeness sake. We need the following definitions given in [1].

DEFINITION 2 [2]. Let $A, B, S$ and $T$ be mappings of a metric space $(X, d)$ into itself such that $A(X) \subset T(X)$ and $B(X) \subset S(X)$. For $x_{0} \in X$, any sequence $\left\{y_{n}\right\}$ defined by

$$
\begin{aligned}
y_{2 n-1} & =T x_{2 n-1}=A x_{2 n-2}, \\
y_{2 n} & =S x_{2 n}=B x_{2 n-1}
\end{aligned}
$$

for $n \in \mathbb{N}$ (the set of positive integers) is called an $\{S, T\}$-iteration of $x_{0}$ under $A$ and $B$. The following definition was given in [1], but erroneously required that $\delta(\epsilon)<\epsilon$. 
Definition 3. Let $A, B, S$ and $T$ be mappings of a metric space $(X, d)$ into itself. The pair $\{A, B\}$ is called a generalized $(\epsilon, \delta)-\{S, T\}$-contraction if

$$
A(X) \subset T(X), \quad B(X) \subset S(X)
$$

and there exists a function $\delta:(0, \infty) \longrightarrow(0, \infty)$ such that, for any $\epsilon>0, \delta(\epsilon)>\epsilon$, and

$$
\begin{aligned}
\epsilon \leq M(x, y)=\max \{d(S x, T y), d(S x, A x), d(T y, B y), \\
\left.\qquad \frac{1}{2}(d(S x, B y)+d(T y, A x))\right\}<\delta(\epsilon) \Rightarrow d(A x, B y)<\epsilon .
\end{aligned}
$$

Now we state and prove a modified version of the lemma in question.

LEMMA 4. Let $A, B, S$ and $T$ be mappings of a metric space $(X, d)$ into itself and let the pair $\{A, B\}$ be a generalized $(\epsilon, \delta)-\{S, T\}$-contraction. If $x_{0} \in X$ and $\left\{y_{n}\right\}$ is an $\{S, T\}$ iteration of $x_{0}$ under $A$ and $B$, we have the following:

(1) $\lim _{n \rightarrow \infty} d\left(y_{n}, y_{n+1}\right)=0$.

(2) For every $\epsilon>0$, there exists $n_{1} \in \mathbb{N}$ such that, whenever $p, q \geq n_{1}$ and of opposite parity,

$$
\epsilon \leq d\left(y_{p}, y_{q}\right)<\epsilon+r \Longrightarrow d\left(y_{p+1}, y_{q+1}\right)<\epsilon,
$$

where $r=\min \{\epsilon / 2,(\delta(\epsilon)-\epsilon) / 2\}$.

(3) The sequence $\left\{y_{n}\right\}$ is a Cauchy sequence in $X$.

Proof. To prove part (1), first note that, by (3),

$$
\begin{aligned}
& d(A x, B y)=0, \quad \text { if } M(x, y)=0, \\
& d(A x, B y)<M(x, y), \quad \text { otherwise. }
\end{aligned}
$$

Thus, $d(A x, B y) \leq M(x, y)$ for $x, y \in X$. Therefore, if $x_{0} \in X$, (1) and (3) imply that

$$
\begin{aligned}
d\left(y_{2 n}, y_{2 n+1}\right)= & d\left(B x_{2 n-1}, A x_{2 n}\right) \\
= & d\left(A x_{2 n}, B x_{2 n-1}\right) \leq M\left(x_{2 n}, x_{2 n-1}\right) \\
= & \max \left\{d\left(S x_{2 n}, T x_{2 n-1}\right), d\left(S x_{2 n}, A x_{2 n}\right), d\left(T x_{2 n-1}, B x_{2 n-1}\right),\right. \\
& \left.\frac{1}{2}\left(d\left(S x_{2 n}, B x_{2 n-1}\right)+d\left(T x_{2 n-1}, A x_{2 n}\right)\right)\right\} \\
= & \max \left\{d\left(y_{2 n}, y_{2 n-1}\right), d\left(y_{2 n}, y_{2 n+1}\right), d\left(y_{2 n-1}, y_{2 n}\right),\right. \\
& \left.\frac{1}{2}\left(d\left(y_{2 n}, y_{2 n}\right)+d\left(y_{2 n-1}, y_{2 n+1}\right)\right)\right\} \\
\leq & \max \left\{d\left(y_{2 n}, y_{2 n-1}\right), d\left(y_{2 n}, y_{2 n+1}\right),\right. \\
& \left.\frac{1}{2}\left(d\left(y_{2 n-1}, y_{2 n}\right)+d\left(y_{2 n}, y_{2 n+1}\right)\right)\right\} \\
\leq & \max \left\{d\left(y_{2 n}, y_{2 n-1}\right), d\left(y_{2 n}, y_{2 n+1}\right)\right\} .
\end{aligned}
$$

Now if $M\left(x_{2 n}, x_{2 n-1}\right)=0$, by the above, we know

$$
d\left(y_{2 n}, y_{2 n-1}\right)=d\left(y_{2 n}, y_{2 n+1}\right)=0 \text {. }
$$


But if $M\left(x_{2 n}, x_{2 n-1}\right)>0,(5)$ and the above imply that

$$
d\left(y_{2 n}, y_{2 n+1}\right)<M\left(x_{2 n}, x_{2 n-1}\right) \leq \max \left\{d\left(y_{2 n}, y_{2 n-1}\right), d\left(y_{2 n}, y_{2 n+1}\right)\right\},
$$

i.e.,

$$
d\left(y_{2 n}, y_{2 n+1}\right)<d\left(y_{2 n}, y_{2 n-1}\right) .
$$

Thus, in any event, we have

$$
d\left(y_{2 n}, y_{2 n+1}\right) \leq M\left(x_{2 n}, x_{2 n-1}\right) \leq d\left(y_{2 n}, y_{2 n-1}\right)
$$

for $n \in X$. Similarly,

$$
d\left(y_{2 n+1}, y_{2 n+2}\right) \leq M\left(x_{2 n+1}, x_{2 n}\right) \leq d\left(y_{2 n}, y_{2 n+1}\right)
$$

for $n \in X$. Thus $s=\left\{d\left(y_{k}, y_{k+1}\right)\right\}$ is nonincreasing and is bounded below by 0 . Hence, $s$ converges to $t \in[0, \infty)$, the greatest lower bound of $s$. If $t=0$, we are done. So, suppose that $t>0$. Since $s$ converges in a nonincreasing manner to $t$, (10) yields $m \in \mathbb{N}$ such that

$$
t \leq M\left(x_{2 m}, x_{2 m-1}\right)<\delta(t) .
$$

But then (3) implies that

$$
d\left(A x_{2 m}, B x_{2 m-1}\right)=d\left(y_{2 m+1}, y_{2 m}\right)<t,
$$

which contradicts the fact that $t$ is the greatest lower bound of $s$. Thus part (1) is true.

Now we prove part (2). Let $\epsilon>0$. Part (1) permits us to choose $n_{1} \in \mathbb{N}$ such that

$$
d\left(y_{n}, y_{n+1}\right)<\frac{r}{2} \text { for } n \geq n_{1},
$$

where $r=\min \{\epsilon / 2,(\delta(\epsilon)-\epsilon) / 2\}$. Let $p, q \in \mathbb{N}$ such that $p, q \geq n_{1}$, where $p=2 n$ and $q=2 m-1$. Suppose that

$$
\epsilon \leq d\left(y_{p}, y_{q}\right)=d\left(y_{2 n}, y_{2 m-1}\right)<\epsilon+r .
$$

Keeping (1), (3), (14) and (15) in mind, we can write the following:

$$
\begin{aligned}
\epsilon \leq d\left(y_{p}, y_{q}\right)= & d\left(S x_{2 n}, T x_{2 m-1}\right) \leq M\left(x_{2 n}, x_{2 m-1}\right) \\
= & \max \left\{d\left(S x_{2 n}, T x_{2 m-1}\right), d\left(S x_{2 n}, A x_{2 n}\right), d\left(T x_{2 m-1}, B x_{2 m-1}\right),\right. \\
& \left.\frac{1}{2}\left(d\left(S x_{2 n}, B x_{2 m-1}\right)+d\left(T x_{2 m-1}, A x_{2 n}\right)\right)\right\} \\
= & \max \left\{d\left(y_{p}, y_{q}\right), d\left(y_{p}, y_{p+1}\right), d\left(y_{q}, y_{q+1}\right),\right. \\
& \left.\frac{1}{2}\left(d\left(y_{p}, y_{q+1}\right), d\left(y_{q}, y_{p+1}\right)\right)\right\} \\
= & \max \left\{d\left(y_{p}, y_{q}\right), \frac{1}{2}\left(d\left(y_{p}, y_{q+1}\right)+d\left(y_{q}, y_{p+1}\right)\right)\right\} \\
\leq & \max \left\{d\left(y_{p}, y_{q}\right), \frac{1}{2}\left(2 d\left(y_{p}, y_{q}\right)+d\left(y_{q}, y_{q+1}\right)+d\left(y_{p}, y_{p+1}\right)\right)\right\} \\
\leq & d\left(y_{p}, y_{q}\right)+\frac{r}{2}<\epsilon+\frac{3 r}{2}<\epsilon+2 r \leq \epsilon+(\delta(\epsilon)-\epsilon)=\delta(\epsilon) .
\end{aligned}
$$


Thus we have $\epsilon \leq M\left(x_{2 n}, x_{2 m-1}\right)<\delta(\epsilon)$, and so (3) implies that

$$
d\left(y_{p+1}, y_{q+1}\right)=d\left(A x_{2 n}, b x_{2 m-1}\right)<\epsilon,
$$

as desired.

To prove part (3), let $\alpha=2 \epsilon>0$ and let $r=\min \{\epsilon / 2,(\delta(\epsilon)-\epsilon) / 2\}$. Part (2) of the lemma yields $n_{1} \in \mathbb{N}$ such that, whenever $p, q \in \mathbb{N}$ and $p, q>n_{1}$, then

$$
d\left(y_{p+1}, y_{q+1}\right)<\epsilon \text { if } \epsilon \leq d\left(y_{p}, y_{q}\right)<\epsilon+r \text { and } p, q \text { are of opposite parity. }
$$

And part (1) of the lemma permits us to choose $n_{0} \in \mathbb{N}$ such that $n_{0}>n_{1}$ and

$$
d\left(y_{m}, y_{m+1}\right)<\frac{r}{6}
$$

for $m \geq n_{0}$. Now we let $q>p \geq n_{0}$-so that both (18) and (19) hold-and show that $d\left(y_{p}, y_{q}\right)<\alpha$, thereby proving that $\left\{y_{n}\right\}$ is a Cauchy sequence in $X$. So suppose that

$$
d\left(y_{p}, y_{q}\right) \geq \alpha=2 \epsilon \text {. }
$$

To show that (20) produces a contradiction, we first want to choose an $m>p$ such that

$$
\epsilon+\frac{r}{3}<d\left(y_{p}, y_{m}\right)<\epsilon+r \text { with } p \text { and } m \text { of opposite parity. }
$$

To this end, let $k$ be the smallest integer greater than $p$ such that $d\left(y_{p}, y_{k}\right)>\epsilon+$ $(r / 2)$. The integer $k$ exists by (20) since $r<\epsilon$. Moreover, we have

$$
d\left(y_{p}, y_{k}\right)<\epsilon+\frac{2 r}{3} \text {. }
$$

For otherwise, $\epsilon+2 r / 3 \leq d\left(y_{p}, y_{k-1}\right)+d\left(y_{k-1}, y_{k}\right)<d\left(y_{p}, y_{k-1}\right)+r / 6$, since $k-1 \geq$ $p \geq n_{0}>n_{1}$, and therefore

$$
\epsilon+\frac{r}{2}<d\left(y_{p}, y_{k-1}\right)
$$

Since $k-1 \geq p$, (23) implies that $k-1>p$. But then (23) contradicts the choice of $k$. We thus have

$$
\epsilon+\frac{r}{2}<d\left(y_{p}, y_{k}\right)<\epsilon+\frac{2 r}{3} .
$$

So, if $p$ and $k$ are of opposite parity, we can let $m=k$ in (24) to obtain (21). If $p$ and $k$ are of like parity, $p$ and $k+1$ are opposite parity. Since $d\left(y_{k}, y_{k+1}\right)<r / 6$ by (19), the triangle inequality and (24) imply that

$$
\epsilon+\frac{r}{3}<d\left(y_{p}, y_{k+1}\right)<\epsilon+\frac{5 r}{6} .
$$

In this instance, we let $m=k+1$. In any event, by (24) and (25), we can choose $m$ such that $m$ and $p$ are of opposite parity and (21) holds. But then, since $p, m \geq n_{0}$, (19) and (21) imply that

$$
\epsilon+\frac{r}{3}<d\left(y_{p}, y_{m}\right) \leq d\left(y_{p}, y_{p+1}\right)+d\left(y_{p+1}, y_{m+1}\right)+d\left(y_{m+1}, y_{m}\right) .
$$

Therefore, by (21) and (18), we have

$$
\epsilon+\frac{r}{3}<\frac{r}{3}+d\left(y_{p+1}, y_{m+1}\right)<\frac{r}{3}+\epsilon .
$$

This is the anticipated contradiction. This completes the proof. 
ACKNOWLEDGements. The authors wish to thank Dr. A. S. Ranadive and Dr. A. K. Sinha for alerting them to the difficulties in [1]. The first author (YJC) was supported in part by the Basic Science Research Institute Program, Ministry of Education, Korea, 1998, Project No. BSRI-98-1405.

\section{REFERENCES}

[1] Y. J. Cho, P. P. Murthy, and G. Jungck, A common fixed point theorem of Meir and Keeler type, Internat. J. Math. Math. Sci. 16 (1993), no. 4, 669-674. CMP 1234811. Zbl 790.54054 .

[2] G. Jungck, Compatible mappings and common fixed points. II, Internat. J. Math. Math. Sci. 11 (1988), no. 2, 285-288. MR 89h:54029. Zbl 647.54035.

Cho: Department of Mathematics, Gyeongsang NATIONAL UniVersity, ChinJu 660-701, KOREA

E-mail address: yicho@nongae.gsnu.ac. kr

Murthy: Department of Mathematics, Arignar AnNa Govt. Arts College, Karaikal (PONDICHERRY V. T.) 609605, INDIA

JungCK: DePartment of Mathematics, Bradley University, Peoria, IL 61625, USA 


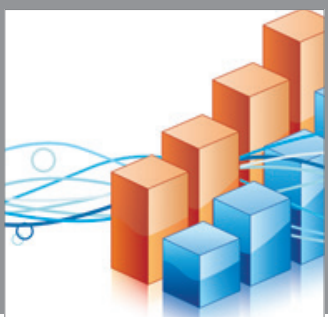

Advances in

Operations Research

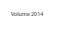

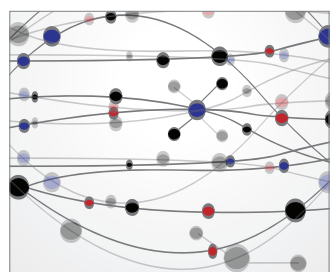

\section{The Scientific} World Journal
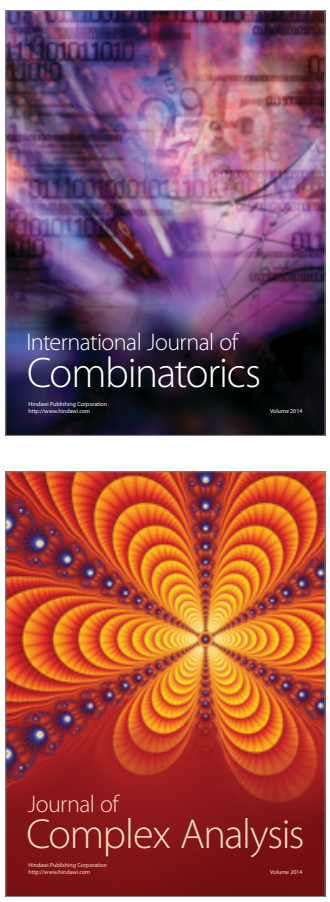

International Journal of

Mathematics and

Mathematical

Sciences
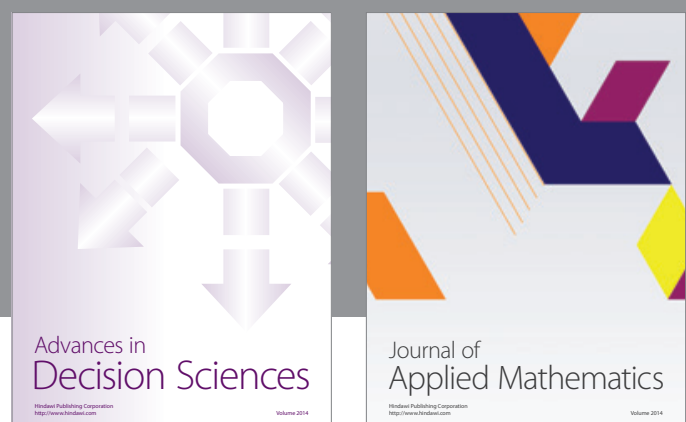

Journal of

Applied Mathematics
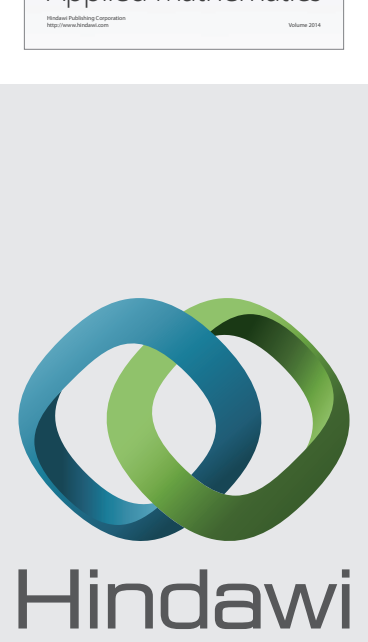

Submit your manuscripts at http://www.hindawi.com
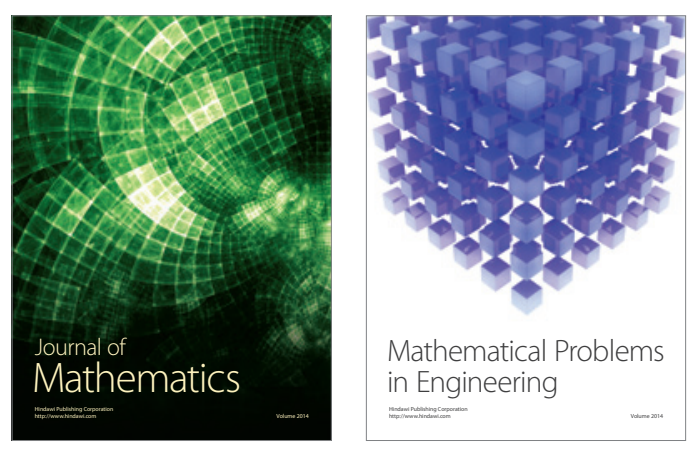

Mathematical Problems in Engineering
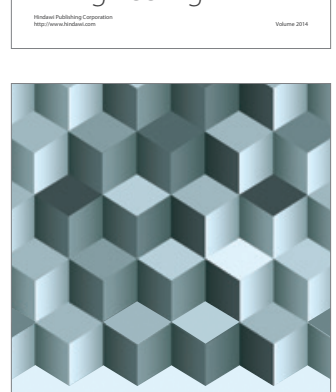

Journal of

Function Spaces
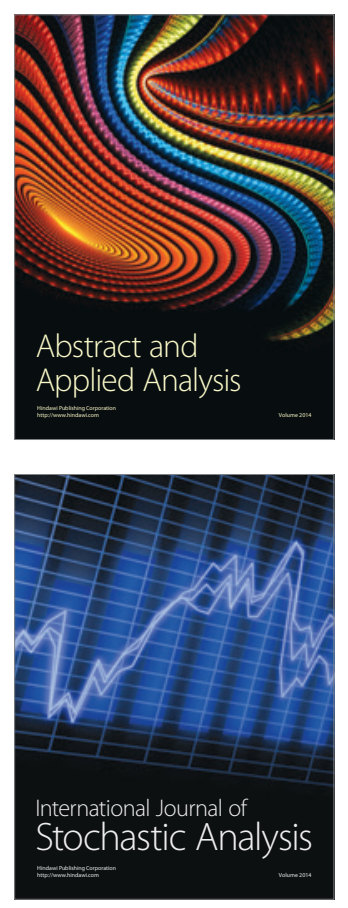

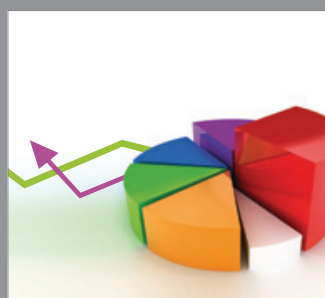

ournal of

Probability and Statistics

Promensencen
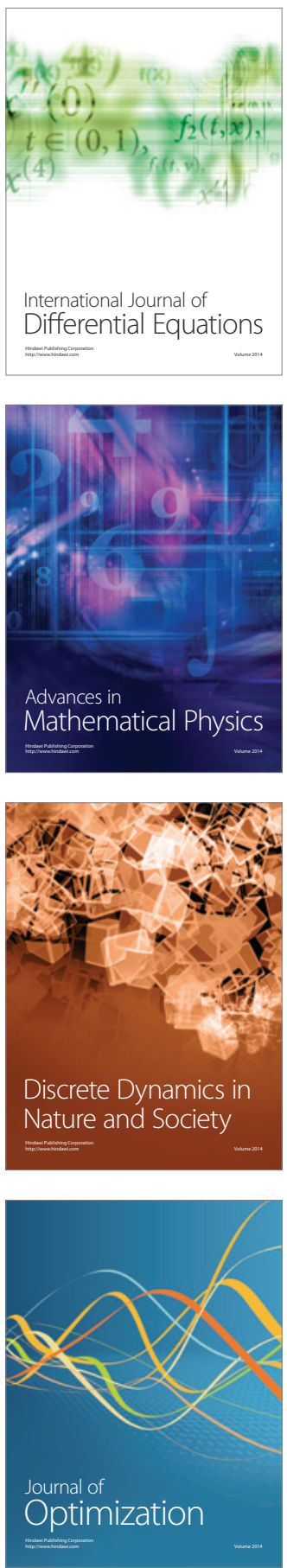